\title{
Magnet Device
}

National Cancer Institute

\section{Source}

National Cancer Institute. Magnet Device. NCI Thesaurus. Code C50040.

A device that attracts iron and produces a magnetic field. 